\title{
Environmental health in public health community practice: An integrative review of the literature
}

\author{
Marta Regina Cezar-Vaz ${ }^{1^{*}}$, Clarice Alves Bonow ${ }^{2}$, Cynthia Fontella Sant' Anna $^{2}$, \\ Laurelize Pereira Rocha ${ }^{1}$, Marlise Capa Verde de Almeida ${ }^{1}$, Mara Regina Santos da Silva ${ }^{1}$ \\ ${ }^{1}$ School of Nursing, Federal University of Rio Grande/RS, Rio Grande City in Rio Grande do Sul, Brazil; \\ *Corresponding Author: cezarvaz@vetorial.net \\ ${ }^{2}$ Federal University of Pampa, Uruguaiana, Brazil
}

Received 7 June 2013; revised 7 July 2013; accepted 30 July 2013

Copyright (C 2013 Marta Regina Cezar-Vaz et al. This is an open access article distributed under the Creative Commons Attribution License, which permits unrestricted use, distribution, and reproduction in any medium, provided the original work is properly cited.

\begin{abstract}
It is understood that the performance of Public Health Nursing is indispensable for the development of sustainable health communities, with regard to sub-standard living conditions in environments that include physical, chemical and biological factors influencing these conditions. This work is in an integrative review which aims to characterize how Environmental Health appears in scientific Public Health Nursing production, for the development of community health. Out of 442 articles, 30 met the search criteria. The publications covered contamination and exposure to environmental risks; strengthening of community groups for environmental health and workforce development of public health nursing for community practice in environmental health. The results summarized in the present study support the growing trend of interest in Environmental Health as knowledge which is essential to Public Health Nursing practice in the community.
\end{abstract}

Keywords: Public Health Nursing; Environmental Health; Community Health

\section{INTRODUCTION}

The Millennium Development Goals of the United Nations include the relationship between human health and environmental health $(\mathrm{EH})$ sustainability [1]. In this perspective, it is understood that the performance of Public Health (PH) Nursing becomes indispensable, through its theoretical and practical skills and commitment to social justice, with the aim of minimizing inequalities in relation to sub-standard living conditions in environments which include physical, chemical and biological factors
[2] which influence these conditions.

The aim of this review is to characterize how EH appears in PH Nursing scientific production, for the development of community health. According to the World Health Organization (WHO), [3] community health corresponds to a combined science of values, beliefs and skills directed towards the maintenance and development of health for all people through collective and social action. Programs, services and institutions involved prioritize disease prevention and the needs of the population as a whole [3]. We are of the belief that PH Nursing is a sub-area of nursing knowledge which is building a body of knowledge tied to environmental sciences. In other words, PH Nursing has in its production, scientific evidence which is included in the interdisciplinary field of $\mathrm{EH}$, which is the desired relationship with the health of communities.

The aim is to explain the themes and forms of apprehension about EH which are included in the cataloging of peer reviewed articles, defining the scope and limits of the findings presented here. Future potential for other research review is also highlighted.

\section{METHODS}

To achieve this goal, the integrative review method was preferred, which allows for complete synthesized research and for obtaining evidence from the theme, EH in the sub-area of PH Nursing. For this operational review there were six stages: defining the guiding question; establishment of criteria for inclusion/exclusion for the selection of scientific articles; definition of the information to be extracted from selected articles; analysis of the included studies; interpretations of the results and; presentation of an integrative review [4]. The quality of the evidence of the texts selected were classified into seven levels: 1 evidence from a systematic review or meta-ana- 
lysis of randomized controlled trials or derived from clinical guidelines based on systematic reviews of randomized controlled trials; level 2 evidence from at least one well delineated randomized controlled Trial; level 3 evidence from well-designed clinical trials without randomization; level 4 evidence from cohort and case-control well delineated trials; level 5 evidence from a systematic review of descriptive and qualitative studies; level 6 evidence from a descriptive or qualitative study and; level 7 evidence from opinion of authorities and/or report of expert committees [5].

The guiding question was: How does Environmental Health appear in the scientific production of Public Health Nursing, for the development of community health?

The selection of studies was focused on $\mathrm{EH}$ and as a collective object and study and intervention in the subarea of PH Nursing. Thus, studies of interest sought to address communities in need of $\mathrm{EH}$. To help standardize the research, the definition of EH from WHO [2] was adopted. EH is related to the physical, chemical and biological external factors, which may interfere with human behavior. EH is comprised of the evaluation and control of those environmental factors which have the potential to adversely affect health. This is achieved through disease prevention and healthy environments. It should be noted that this definition excludes behavior not related to the environment, social and cultural environments and genetics [2]. The choice of a social-historical scope of the definition in different areas of knowledge, which makes the multi-disciplinary knowledge productive and which is the particularity of PH Nursing, is explained.

\subsection{Study Selection Criteria}

The peer reviewed literature was screened to identify articles documenting the production of $\mathrm{PH}$ Nursing in relation to the EH community, as aforesaid. The EH includes any external factor related to people living in particular surroundings (that which is around people), understood as a community setting. Therefore, it is reiterated that the review was restricted to studies that highlight $\mathrm{EH}$ in relation to the collective object and community of the study and intervention in the sub-area of $\mathrm{PH}$ Nursing. Dissertations, theses and texts without abstracts were not included. Studies that did not show at least one nurse as an author were excluded. The study was limited to articles that were available in English, Portuguese or Spanish. Only studies which constitute research with empirical data in relation to $\mathrm{EH}$ as the collective object and in relation to the community of the study with intervention in the sub-area of PH Nursing were considered in this review.

\subsection{Search Strategy}

The following electronic databases were searched for the period January 1992 to December 2012: CINAHL, Medline, Web of Science, Cochrane Library and Science Direct. The choice of this period is justified, due to the relationship with EH Nursing as an object of study and intervention, from the socio-temporal context of the United Nations Conference on Environment and Development. In addition to this milestone justifies the reported evidence that the formal description of the technical and scientific skills of PH Nursing is not explicit in the scientific community until 1990 [6].

To search the peer reviewed texts, recourse was made to the National Library of Medicine, Medical Subject Headings $\left(\mathrm{MeSH}^{\circledR}\right)$, for confirmation of keywords required, namely: Environmental Health (the science to control or modify conditions, influences or forces that surround men/women and that relate to the promotion, establishment and maintenance of health); Public Health Nursing (the area of nursing with a focus on community health through preventive and educational programs, as well as providing treatment services and diagnosis); and Community (elements that characterize a population; apply in determining the need for and use of health services).

The inclusion or exclusion of studies was conducted by two independent evaluators. There is an agreement among evaluators in all the stages.

\section{RESULTS}

\section{Inclusion, Exclusion and Presentation of Studies}

Throughout the researched literature, 442 publications were identified. Most publications were indexed in Medline $(n=130)$, followed by CINAHL $(n=124)$, Cochrane Library $(n=179)$ and Science Direct $(n=9)$. After identification of the results, duplicated articles were removed and 57 publications were eliminated. Publications which did not have at least one nurse as an author were also withdrawn, eliminating 26 publications and five publications which appeared in German, Greek, Slovenian, Chinese and Japanese. In the first screening encountered in the title, 359 publications were analyzed. Such analysis enabled the identification of 114 relevant references. Of the 245 articles excluded after reading the titles, 59 did not respond to the study theme and 186 had no empirical research methodology. The second screening encountered in the summary of the articles, identified 30 relevant references. The 84 excluded articles were not appropriate to the study theme (Figure 1).

Of the 30 included studies, eighteen (60\%) addressed contamination and exposure to environmental risks; four (13\%) addressed the strengthening of community groups for $\mathrm{EH}$ and eight (27\%) addressed the workforce development of $\mathrm{PH}$ Nursing for community practice in $\mathrm{EH}$ 
(Table 1).

Concerning the publication years, most articles were published in $2010(\mathrm{n}=5)$ (Figure 2).

Regarding the articles, analyzed quality of the evidence in the first subset, "Contamination and exposure to environmental risks", 18 articles (94.4\%) had levels of evidence 6 and 1 article (5.55\%) level 2. In the second subset, "Strengthen community groups for environmental health", 3 articles (75\%) had levels 6 and 1 article (25\%) level 7. In the third subset, "Workforce development of public health nursing for community practice in environmental health", all eight articles analyzed showed level 6 . In all of the analyzed articles, the majority, 28 texts (93.35\%), presented evidence level 6 .

Concerning the impact factor of the journals containing the analyzed publications, the highest was 3.926 of the American Journal of Public Health. The lowest impact factor was the journal Annual Review of Nursing Research (0.182).

Characteristics of studies included in the review, grouped by subject are present in Table 2 .

\section{DISCUSSION}

The scope of this review of studies in the sub-area of PH Nursing regarding EH was predominated by contamination and exposure to environmental risks [7-24]. Added to this are studies which include strengthening community groups for EH; [25-28] and studies that present strategies for workforce development of PH nursing for community practice in EH [29-36].

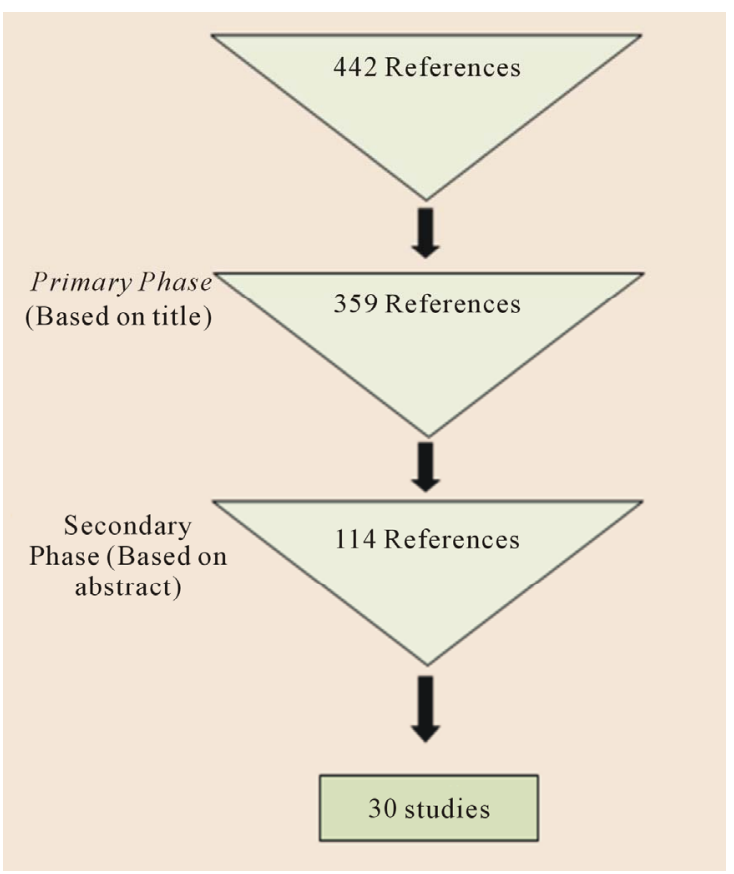

Figure 1. Results during each screening phase and final number of included documents.
Table 1. Subjects addressed in articles included $(n=30)$. Percentages rounded to the nearest whole number.

\begin{tabular}{cc}
\hline Subjects & Percent (\%) \\
\hline $\begin{array}{c}\text { Contamination and exposure to } \\
\text { environmental risks-18 } \\
\text { Strengthening of community groups } \\
\text { for environmental health—- }\end{array}$ & 60 \\
$\begin{array}{c}\text { Workforce development of public health nursing for } \\
\text { community practice in environmental health-8 }\end{array}$ & 27 \\
\hline
\end{tabular}

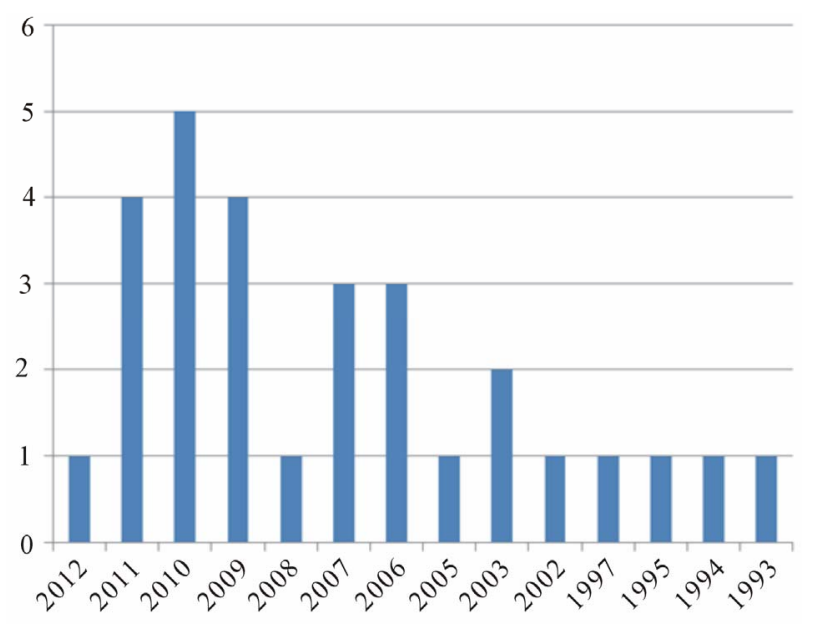

Figure 2. Distribution of publication years of the articles included in the review $(\mathrm{n}=30)$.

\subsection{Contamination and Exposure to Environmental Risks}

In this subset studies were found which had been developed in a rural setting, in the home and at school. This latter is related to environmental pollution produced by tobacco smoke in the school environment [12]. The contamination and exposure of the rural environment include, for example, contamination by asbestos [9]; rural environment contamination by the concentration of animals and their effect on human health; exposure to secondhand smoke in a rural school; [21] the rural home environment as the focus of $\mathrm{PH}$ nurse intervention [11]. It should be noted that explicit means for EH were included in these studies, as, for example, the use of parks for adolescents [19] as a positive element in the construction of EH. Another study related to environmental exposure to smoke from vulnerable groups, is the case of the child whose parents smoke at home [17] as an intervention object for PH Nursing practice. Such studies indicate the different areas that are present in the $\mathrm{EH}$ practice of $\mathrm{PH}$ nursing, highlighting the need for preparation of professionals to work with such diversity.

\subsection{Strengthen Community Groups for Environmental Health}

Positive evidence of $\mathrm{PH}$ Nursing interventions was 
Table 2. Characteristics of studies included in the review, grouped by subject. Dash marks indicate items not reported in the studies.

\begin{tabular}{|c|c|c|c|c|}
\hline Title & Location & Design & Aim & Main results \\
\hline
\end{tabular}

Barriers and

Facilitators in the

Delivery of

Environmental Risk

Reduction by Public

Health Nurses in the

Home Setting [7]

Community-based participatory research (CBPR) approach to study children's health in China:

Experiences

and reflections [8]

Rural Public Health

Policy Models to

Address an Evolving

Environmental

Asbestos Disaster [9]

Effectiveness of a

Household

Environmental

Health Intervention

Delivered

by Rural Public

Health

Nurses [10]

Indoor Air Pollutants and Sick Building Syndrome: A Case Study and

Implications for the

Community

Health Nurse [11]

Secondhand Smoke

Exposure in a Rural

High School [12]

County-Level Social

Environment

Determinants of

Health-Related

Quality of Life

Among US

Adults: A Multilevel

Analysis [13]
United Empirical data
United $\quad \begin{aligned} & \text { Structured } \\ & \text { individual }\end{aligned}$

States individual

drawn from secondary basis. community base with blood samples from the study group and questionnaire.

Identify the factors that contribute to or hinder the ability of public health nurses to reduce environmental hazards in the home environment

Community-based longitudinal study with study group and questionnaire.

Describe the history and asbestos exposure in a rural community and discuss three models that provide insights into public health policies related to rural health and health care for the affected community.

Study with a

randomized sample of

households, using Inform parents in order to

United interviews and

States intervention process on the precautionary risk

of the home environment. reduce the risks in domestic environmental health for their children. blood samples from the

The main factors that affect the ability of public health nurses to reduce environmental hazards in the home environment were lack of training in public health nursing and the lack of relationship with environmental health. Contributing factors were: training and support and personal interest in environmental health.

The CBPR is a systematic approach that equitably involves community and academic partners in the research process involved. The project represented a mutual interest: understanding the effect of lead exposure on children's health. This fact confirms the principle that guides the process of CBPR. The study can be a model for other studies investigating the relationship between environmental pollution and improving environmental health for children.

The multidimensional model provides the basis for addressing the components of both models, the ecological and rural, adding functions and perspectives of local stakeholders impacted by environmental events, e.g. asbestos-related disease.

Nursing intervention produced significant improvements in both outcomes. Such evidence supports the need for a political discussion on the value that is added by nursing interventions in public health and what it can bring to the environmental health of children.
United Cross-sectional

study, non experimental

Multilevel study models were used in which there were several levels to calculate the proportion of United variation of States quality of life (HRQOL), which was explained by the county level contextual variable and normal level.
Analyze air pollutants inside buildings and demonstrate the relationships inside the school building and its effects on health.

Describe pollution by smoke from a rural school.

The concentration of smoke particles was higher in the boys' bathroom.

The analysis showed numerous acute and chronic effects on health associated with exposure of the products studied. The case study demonstrated the imminent need for community health nurses to take on a proactive role in promoting environmental health.
Show that the quality of life of an individual's health is determined not only by their personal characteristics but is also socially determined by the physical and environmental community.
Counties with the lowest socio-economic indicators (high mortality rate and low life expectancy) were associated with greater numbers of unhealthy days. The suicide rate, without health insurance, access to primary care population percent uninsured, primary care facilities, among others, also had an impact but at a lower rate of significance than for the days of unhealthy respondents. 


\section{Continued}

\begin{tabular}{|c|c|c|c|c|}
\hline $\begin{array}{l}\text { Geographic } \\
\text { Information Systems: } \\
\text { A New Tool for } \\
\text { Environmental Health } \\
\text { Assessments [14] }\end{array}$ & $\begin{array}{l}\text { United } \\
\text { States }\end{array}$ & $\begin{array}{l}\text { Survey used to } \\
\text { collect } \\
\text { environmental } \\
\text { exposure and } \\
\text { self-reported } \\
\text { health, with a } \\
\text { sample of people } \\
\text { in an urban } \\
\text { community health } \\
\text { center. }\end{array}$ & $\begin{array}{l}\text { Developing tools for health } \\
\text { professionals who work } \\
\text { with communities to assess } \\
\text { environmental exposures, } \\
\text { evaluate the usefulness of } \\
\text { integrating information } \\
\text { reported by patients on } \\
\text { environmental health with } \\
\text { geographic information } \\
\text { systems. }\end{array}$ & $\begin{array}{l}\text { Common environmental risk factors have been reported, } \\
\text { such as ancient dwellings (93\%), and household smoking } \\
\text { ( } 78 \%) \text {. Health problems including asthma (54\%) and lead } \\
\text { poisoning (14\%) were reported. }\end{array}$ \\
\hline $\begin{array}{l}\text { Environmental } \\
\text { exposure assessment, } \\
\text { pollution sources, and } \\
\text { exposure agents: a } \\
\text { primer for pediatric } \\
\text { Nursing Professionals } \\
\text { [15] }\end{array}$ & $\begin{array}{l}\text { United } \\
\text { States }\end{array}$ & - & $\begin{array}{l}\text { Understanding of } \\
\text { environmental exposure } \\
\text { assessment as a condition to } \\
\text { promote children's } \\
\text { environmental health. }\end{array}$ & $\begin{array}{l}\text { With sufficient knowledge and awareness of the basic } \\
\text { concepts on the assessment of human exposure and the } \\
\text { details on the sources of environmental pollution, a pediatric } \\
\text { nurse can confidently develop his/her clinical practice and } \\
\text { education. Promoting promotion by reducing exposure to } \\
\text { environmental hazards or avoidance. }\end{array}$ \\
\hline
\end{tabular}

Participation in Community Health Screenings: A

Qualitative

Evaluation [16]
United

States

Qualitative study using focus groups, with the use of audio and video data.
Describe the results of a qualitative evaluation of the focus groups organized surroundings with the participation of a semi-rural community in health screening program.

Find predictors for passive exposure to smoke of paternal children, induced in the home or family car.

The areas identified in this assessment represent a set of influences from the context of individual, group and environment in which people were motivated to participate in health screenings in a semi-rural community. The emergence of the three domains of motivators (self-care guidelines, interpersonal influence and accessibility) for participation in sessions in the community reflects an ecological individual, micro, and macro systems. Approaching community participation, from the intersections on the ecological model, is the intersection of intrapersonal and interpersonal dimensions, as well as the explicit macro for social accessibility.

Multivariate analysis revealed that the factors found to mediate paternal household exposure to secondhand smoke

Predictors of
Childhood Exposure to Parental Secondhand Smoke in the House and Family Car [17]
Promoting safe drinking water [18]
Greece

Multivariate epidemiologica analysis

A descriptive exploratory survey with quantitative and qualitative data about beliefs and health practices, satisfaction with health and community Canada services, as well as with the concern for the health of the community. The procedures consisted of household survey interviews, focus groups and telephone

Rural Latino

Youth Park Use:

Characteristics,

United

Park Amenities, and Physical Activity [19]

States
Cross-sectional study on the profile of young people who use community parks.
Evaluate the beliefs and practices of health, satisfaction with health services and community concerns in relation to community health.
Investigate characteristics of young people and behavior that attracts young people to the parks to encourage physical activity in a rural community.
The results indicated that the quality of drinking water is a major concern. Public health nurses as risk communicators play a core role in the environmental health of communities. Although the average ratings for each region indicated that families were relatively satisfied with the services of water and sewage, the central region was significantly less satisfied than all the others.
$<0.001$ ), while having a spouse non-smoker had a protective effect (OR 0, 44, p = 0.026). Adds that parents with low education are more likely to have a spouse who expose their children to secondhand smoke in the family car (OR 1.38 95\% CI: 1.04 to $1.84, \mathrm{p}=0.026)$.

In this study of parks uses by youths there was no association between organized activity participation after school and team identification as a source of motivation for the young becoming active. 


\section{Continued}

Sowing the seeds for sustainable

change: a community-based participatory research partnership for health promotion in Indiana, USA and its aftermath [20]

Environmental health effects of concentrated animal feeding operations: implications for nurses [21]

The role of the community health nurse in environmental health [22]

$\begin{array}{ll}\text { United } & \text { based } \\ \text { States } & \text { participatory } \\ & \text { research (CBPR). }\end{array}$

Analyze the development of the partnership originated on health initiatives, such as the analyzed program (CBPR), from CBPR, the methods have often been disappointing in their ability to explain the and findings and environmental changes that sought to promote healthier lifestyles. community health through the collaborative efforts of confidence on the individual, community, institutional or policy sectors. From the evidence, the following observation for the long term arises.
Self-reported exposure to environmental hazards for workers' environments of concentrated feed and neighboring farms.

Develop diagnostic environmental health of the community, including framework phases: identification of the community with high risk of exposure determining the potential or real answers, and environmental factors has some epidemiological correlation for assisting nursing diagnosis.
Identify evidence of exposure risks to workers' health, the environment for concentrated animal feeding.
The adverse health effects have been found in workers and neighbors. A number of respiratory effects were noted for workers and neighbors, some of which are severe enough to cause workers to leave the industry. The mental health of neighbors seems to suffer as well, mainly because of noxious odors and stress.
Study of systematic evaluation of environmental health, from concepts related to environmental health and chemical contamination in communities.
Chemical contamination affects the health of many communities. The results showed high levels of lead in injury to the community: children are at risk of developing adverse neurobehavioral health effects and pregnant women are at risk of developing adverse reproductive health effects related to various environmental factors, as evidenced by the average blood lead levels in children, exceeding the Centers for Disease Control recommended level of 10 micrograms/dl.
Nursing research in community-based approaches to reduce exposure to secondhand smoke [23]
United States
Presenting community-based and population-based surveys that show evidence for reducing secondhand smoke
Concern is emerging in nursing science exposure to secondhand smoke and nicotine and tobacco dependence, which suggests that the reduction of secondhand smoke is an emerging need for nursing, which explores the link between secondhand smoke exposure to nicotine and tobacco dependence, i.e., it is a reason that the secondhand smoke is a reduction strategy for smoking cessation. Other nursing research is under development in relation to factors that are linked to cessation of smoking.
The role of outcome and efficacy expectations in an intervention designed to reduce infants' exposure to environmental tobacco smoke [24]
Analyze a theoretical framework of an intervention program designed to reduce the exposure of children to environmental tobacco smoke.
The content of the intervention was focused on two psychosocial constructions: expectations of results that can be created in behavior associated with exposure to environmental tobacco smoke and expectations of self-efficacy associated with the mother's ability to engage in such behavior. The authors also reported that the intervention was effective in relation to changing expectations and desired direction. These results suggest that the expected results are mutable and therefore represent important targets for future programs to monitor environmental exposure to tobacco smoke. 


\section{Continued}

Strengthen community groups for environmental health

\begin{tabular}{|c|c|c|c|c|}
\hline $\begin{array}{l}\text { Assessment of } \\
\text { Community } \\
\text { Contamination: A } \\
\text { Critical } \\
\text { Approach [25] }\end{array}$ & $\begin{array}{l}\text { United } \\
\text { States }\end{array}$ & $\begin{array}{l}\text { Analysis on } \\
\text { different data } \\
\text { sources } \\
\text { (government } \\
\text { reports; research } \\
\text { reports; } \\
\text { newspapers and } \\
\text { interviews with } \\
\text { residents) }\end{array}$ & $\begin{array}{l}\text { Analyze two communities } \\
\text { and describe the } \\
\text { interpretation of } \\
\text { environmental risk of its } \\
\text { residents }\end{array}$ & $\begin{array}{l}\text { In an evaluation of nursing in a contaminated community, the } \\
\text { nurse is critical as a source of social facts and the nurse can be } \\
\text { qualified to be an agent of an official or scientific information } \\
\text { agency for residents of contaminated sites. This is because the } \\
\text { communication needs to be conducted with mutual trust, } \\
\text { through a collaborative process of building skills within the } \\
\text { community in order to empower residents and leaders to } \\
\text { independently verify the safety of their community. }\end{array}$ \\
\hline
\end{tabular}

Comprehensive Case study

Evaluation

of a Community

Coalition: A Case

Study of

Environmental

Tobacco Smoke

Reduction [26] conducted with

15 public and

private

United organizations

States focused on

prevention

coalition against

tobacco.
Present a methodology and conceptual framework based on the results of programs used to evaluate the performance and impact of a coalition of local community.

The analysis of co-development alliance in Douglas County, with regard to the final results of the smoking prevention program; the authors emphasize that comparative measurements must be performed every year. Identify that there are strong reasons for the co-alliance to continue, citing among these: the federal program is in decentralization and community is the focus for local and state governments; funding favoring collective community work and strengthen alliance application programs in co-covenant co-alliances to represent are media health programs. Thus, the public health nurses represent excellent resources for the evaluation of services, due to their clinical experience, their knowledge of community resources and their education focused on community groups and individuals.

Ethnographic. United conducted with States

Ecological

Community

Health [27]

Evidence-based advocacy: using Photovoice to identify barriers and facilitators for community participation after spinal cord injury? [28] The study was 33 participants in a community.

Explore the relationships between health, environment and culture from the cultural context of a community.

Describe the photovoice method applied to individuals with spinal cord injury in order to gather evidence of the

Communitybased participatory research (CBPR)
The results presented allowed for reflection on the story of overcoming (winning over) the community. Through the process of empowerment of individuals in the community, the people of San Jose had voice, structure and action.

The Photovoice is effective to empower individuals with spinal cord injury to address the environmental factors that affect their participation in the community.

\section{Workforce development of the public health nursing for community practice in environmental health}

affect their community involvement.

\begin{tabular}{|c|c|c|c|}
\hline $\begin{array}{l}\text { Knowledge of nurses } \\
\text { about the Family } \\
\text { Health Strategy about } \\
\text { health service waste } \\
\text { [29] }\end{array}$ & Brazil & Qualitative & $\begin{array}{l}\text { Analyze the knowledge } \\
\text { of nurses working in the } \\
\text { Family Health Strategy } \\
\text { refers to the problem of } \\
\text { waste mismanagement of } \\
\text { health services, the need to } \\
\text { adequately meet the } \\
\text { relevant standards and even } \\
\text { including the professionals } \\
\text { involved in the management } \\
\text { process. }\end{array}$ \\
\hline
\end{tabular}

Developing the community environmental health role of the nurse [30]
Focus group with community

Scotland nurses and community members
Investigate the environmental health concerns of community members from a town in Scotland.
The results showed that nine of the ten nurses interviewed were able to diagnose the situation in which the residues are within their unit. However, despite the existence of a significant knowledge on the subject, there is still need to work on awareness and development of best practice waste management of health services. 


\section{Continued}

Incorporating environmental health into nursing practice: a case study on indoor air quality [31]

Barriers to population-focused health promotion: the experience of public health nurses in the province of Manitoba [32]

\section{$\begin{array}{ll} & \text { were conducted } \\ \text { Canada } \quad \text { with } 24 \text { public }\end{array}$} health nurses from three different geographical areas.
United

States public health nursing role in environmental health [33]
Case study grounded in the experiences of nurses who work in reducing environmental risks.

Qualitative, descriptive and exploratory. Interviews
Develop skills assessment in environmental health for public health nurses.
The authors on potential agents which can cause damage to the health of children, such as carbon dioxide, mold and radon. The latter it is a chemical element that may be present in concrete.
Present a study on the prospects for public health nurses about the nature of their practice of health promotion, highlighting perceptions of population barriers with a focus on health promotion.
The perceptions of nurses about their practices were similar, although they were in different places. Barriers to community health promotion were identified in relation to public health nurses and in relation to organizational factors, such as culture and site policies. The results highlight a gap between the theory and that the population with a focus on health promotion is the heart of the practice of public health nurse.

\section{Community} environmental quality knowledge and awareness among nurses: United and piloting an assessment

The results show that education for environmental health community is the primary responsibility for environmental health because it enables communities to minimize exposure to hazardous wastes present in the community setting.
Nurses' role in children's environmental health Stated protection [35]
Framing personal risk in public health nursing [36]
Qualitative
Identify areas of deficiency in relation to children's environmental health action for public health nurses.
The results indicated that the study participants $(n=34)$ prioritize environmental issues to plan future intervention activities (for example, continuing education).
Qualitative (thematic analysis). 56 public health nurses were interviewed.
Conduct thematic analysis of the risks present in the workplace of public health nursing
The authors found that in addressing environmental health with children, nurses' occupation areas expanded to include preventive counseling, health education and environmental health research.
The authors presented four categories to determine the environmental risks of the work of public health nursing, which are: become aware of and recognize influences; make comparisons and know your rights and freedom. The results also showed that $62 \%$ of nurses questioned, were not concerned about the risks of the workplace. The authors believe that it is disturbing to think that the same workers who promote health do not care about their own. found, first to reduce contamination and exposure to environmental risks and second, to develop interventions with communities to create and strengthen the EH community One of the statements found a link to risk perception of social groups present in the particular surroundings of a community (environment).

Study conducted in two different communities in Arizona/USA [25] identifies that the experiences of resi- dents with contamination and exposure to environmental hazards coincide with the degree of confidence in the public sector, (level of government) [26]. This means that knowledge about specific conditions of contamination and exposure is associated with confidence that this fact is true and even when not living it as an event; it is true if you believe in who is advertising it as true fact. Confidence increases in direct relation to the truth of the clari- 
fied and believed social fact. The process of developing individual skills that focus on community health as an explicit element of the complexity of knowledge to work in $\mathrm{EH}[27,28]$.

\subsection{Workforce Development of Public Health Nursing for Community Practice in Environmental Health}

Studies addressing the contamination and exposure to risks in households conducted in the United States demonstrate the ability of the $\mathrm{PH}$ nurse to reduce risks in the home environment, linked to the training and institutional support and community development of these skills. They reinforce the fact that the $\mathrm{PH}$ nurse is properly positioned to promote the families' and communities' health through the reduction of risks in the home environment $[30,31,34,35]$.

EH represents a challenge in the sub-area of PH Nursing, as a theoretical object and as an intervention object $[10,30]$. In both cases a technical and methodological contribution is required which is able to produce scientific evidence for the development of nursing actions [30, $32,34,36]$. It is also assumed that it is a complex interdisciplinary field in which the nurse is included in the production of knowledge.

This review has revealed areas for future research. Future review studies could examine the relationship between the theory and what is applied in the EH community and in training PH Nursing. Studies [37-41] outside the scope of this review show the relevance of EH science as being indispensable for the formation of skills for nursing work in communities as a collective object of EH [37]. For this a body of knowledge about contamination and exposure to environmental risks and their potential effects on human health is necessary, [38,39] as well as learning theoretical framework for the construction of $\mathrm{EH}$ as a form of social justice and reducing inequitable health conditions, [40] by building healthy environments in partnership with community groups [41].

The possible errors in identification and inclusion of articles were minimized by the inclusion of a second reviewer. As the studies were limited in number, used various methods and metrics and were conducted in several countries, the results cannot be generalized. There was no intent to carry a weight value of the findings of studies to establish the quality of the study. The development of $\mathrm{PH}$ actions to achieve social justice corresponds to the understanding that $\mathrm{EH}$ is a phenomenon and that nursing in PH is a workforce capable of producing healthy living conditions for different social groups. This means that nursing intervention with communities constitutes a workforce for the production of an EH community.

\section{CONCLUSION}

This review identified EH in $\mathrm{PH}$ Nursing scientific production related to problems of contamination and exposure to environmental risks (rural, home environment, school environment in relation to pollution caused by smoking), among others. The review shows that the PH nurse operates in $\mathrm{EH}$, focused on problems traditionally recognized in this field with, however, participatory approaches in their community intervention. The results summarized in the present study support the growing trend of interest in $\mathrm{EH}$ as essential knowledge for the practice of the community PH nurse.

\section{REFERENCES}

[1] United Nations (2011) The millennium development goals report. New York.

[2] (WHO) World Health Organization (2013) Environmental health. Health topics.

[3] (WHO) World Health Organization (2004) A glossary of terms for community health care and services for older persons. World Health Organizations, Geneva.

[4] Whittemore, R. and Knafl, K. (2005) The integrative review: Updated methodology. Journal of Advanced Nursing, 52, 546-553. doi:10.1111/j.1365-2648.2005.03621.x

[5] Melnyk, B.M. and Fineout-Overholt, E. (2005) Making the case for evidence-based practice. In: Melnyk, B.M. and Fineout-Overholt, E., Eds., Evidence-Based Practice in Nursing \& Healthcare. A Guide to Best Practice, Lippincot Williams \& Wilkins, Philadelphia.

[6] Sánchez, M.E.G. and Encarna, G.P. (2004) Ecology as a center of interest. Revista de Enfermería, 27, 21-28.

[7] Tinker, E., Postma, J. and Butterfield, P. (2011) Barriers and facilitators in the delivery of environmental risk reduction by public health nurses in the home setting. Public Health Nursing, 28, 35-42. doi:10.1111/j.1525-1446.2010.00887.x

[8] Liu, J., McCauley, L., Leung, P., Wang, B., Needleman, H. and Pinto-Martin, J. (2011) Community-based participatory research (CBPR) approach to study children's health in China: Experiences and reflections. International Journal of Nursing Studies, 48, 904-913. doi:10.1016/j.ijnurstu.2011.04.003

[9] Kuntz, S.W., Winters, C.A., Hill, W.G., Weinert, C., Rowse, K., Hernandez, T., et al. (2009) Rural public health policy models to address and evolving environmental asbestos disaster. Public Health Nursing, 26, 70-78. doi:10.1111/j.1525-1446.2008.00755.x

[10] Butterfield, P.G., Hill, W.A., Postma, J., Butterfield, P.W. and Odom-Maryon, T. (2011) Effectiveness of a household environmental health intervention delivered by rural public health nurses. Research and Practice, 1, S262S270. doi:10.2105/AJPH.2011.300164

[11] Tsacoyianis, R. (1997) Indoor air pollutants and sick building syndrome: A case study and implications for the community health nurse. Public Health Nursing, 14, 58- 
75. doi:10.1111/j.1525-1446.1997.tb00411.x

[12] Lee, K., Hahm, E.J., Riker, C.A., Hoehne, A., White, A., Greenwell, D., et al. (2007) Secondhand smoke exposure in a rural high school. The Journal of School Nursing, 23, 222-228. doi:10.1177/10598405070230040701

[13] Jia, H., Moriarty, D.G. and Kanarek, N. (2009) County-level social environment determinants of health-related quality of life among US adults: A multilevel analysis. Journal of Community Health, 34, 430-439. doi:10.1007/s10900-009-9173-5

[14] Choi, M., Afzal, B. and Sattler, B. (2006) Geographic information systems: A new tool for environmental health assessments. Public Health Nursing, 23, 381-391. doi:10.1111/j.1525-1446.2006.00577.x

[15] Shendell, D.G. and Pike-Paris, A. (2007) Environmental exposure assessment, pollution sources, and exposure agents: A primer for pediatric nursing professionals. Pediatric Nursing, 33, 179-182.

[16] Engebretson, J., Mahoney, J.S. and Walker, G. (2005) Participation in community health screenings: A qualitative evaluation. Journal of Community Health Nursing, 22, 7792. doi:10.1207/s15327655jchn2202_2

[17] Mantziou, V., Vardavas, C.I., Kletsiou, E. and Priftis, K.N. (2009) Predictors of childhood exposure to parental secondhand smoke in the house and family car. International Journal of Environmental Research and Public Health, 6, 433-444. doi:10.3390/ijerph6020433

[18] Pike-MacDonald, S., Best, D.G., Twomey, C., Bennett, L. and Blakeley, J. (2007) Promoting safe drinking water. Canadian Nurse, 14-19.

[19] Perry, C.K., Saelens, B.E. and Thompson, B. (2011) Rural latino youth park use: Characteristics, park amenities, and physical activity. Journal of Community Health, 36, 389-397. doi:10.1007/s10900-010-9320-z

[20] Minkler, M., Vásquez, V.B., Warner, J.R., Steussey, H. and Facente, S. (2006) Sowing the seeds for sustainable change: A community-based participatory research partnership for health promotion in Indiana, USA and its aftermath. Health Promotion International, 21, 293-300. doi:10.1093/heapro/dal025

[21] McElroy, K.G. (2010) Environmental health effects of concentrated animal feeding operations: Implications for nurses. Nursing Administration Quarterly, 34, 311-319. doi:10.1097/NAQ.0b013e3181f5649c

[22] Neufer, L. (1994) The role of the community health nurse in environmental health. Public Health Nursing, 11, 155162. doi:10.1111/j.1525-1446.1994.tb00395.X

[23] Hahn, E.J., Ashford, K.B., Okoli, C.T., Rayens, M.K., Ridner, S.L. and York, N.L. (2009) Nursing research in community-based approaches to reduce exposure to secondhand smoke. Annual Review of Nursing Research, 27, 365-391. doi:10.1891/0739-6686.27.365

[24] Strecher, V.J., Bauman, K.E., Boat, B., Fowler, M.G., Greenberg, R. and Stedman, H. (1993) The role of outcome and efficacy expectations in an intervention designed to reduce infants' exposure to environmental tobacco smoke. Health Education Research, 8, 137-143. doi:10.1093/her/8.1.137
[25] Clark, L., Barton, J.A. and Brown, N.J. (2002) Assessment of community contamination: A critical approach. Public Health Nursing, 19, 354-365. doi:10.1046/j.1525-1446.2002.19505.x

[26] Cramer, M.E., Mueller, K.J. and Harrop, D. (2003) Comprehensive evaluation of a community coalition: A case study of environmental tobacco smoke reduction. Public Health Nursing, 20, 464-477. doi:10.1046/j.1525-1446.2003.20607.x

[27] Bent, K.N. (2003) “The people know what they want”: An empowerment process of sustainable, ecological community health. Advances in Nursing Science, 26, 215-226.

[28] Newman, S.D. (2010) Evidence-based advocacy: Using photovoice to identify barriers and facilitators to community participation after spinal cord injury. Rehabilitation Nursing, 35, 47-59. doi:10.1002/j.2048-7940.2010.tb00031.x

[29] Santos, M.A. and Souza, A.O. (2012) Knowledge of nurses of the Family Health Strategy on health services waste [in Portuguese]. The Brazilian Nursing Journal, 65, 645-652. doi:10.1590/S0034-71672012000400014

[30] Carnegie, E. and Kiger, A. (2010) Developing the community environmental health role of the nurse. British Journal of Community Nursing, 15, 298-305.

[31] Barnes, G., Fisher, B., Postma, J., Harnish, K., Butterfield, P. and Hill, W. (2010) Incorporating environmental health into nursing practice: A case study on indoor air quality. Continuing Nursing Education, 36, 33-52.

[32] Cohen, B. (2006) Barriers to population-focused health promotion: The experience of public health nurses in the province of Manitoba. The Canadian Journal of Nursing Research, 38, 52-67.

[33] Phillips, L. (1995) Chattanooga Creek: A case study of the public health nursing role in environmental health. Public Health Nursing, 12, 335-340. doi:10.1111/j.1525-1446.1995.tb00157.x

[34] Shendell, D.G., Alexander, M.S. and Huang, Y. (2010) Community environmental quality knowledge and awareness among nurses: Developing and piloting an assessment survey in schools. Pediatric Nursing Journal, 36, 18-23.

[35] Sattler, B. and Davis del, B.A. (2008) Nurses' role in children's environmental health protection. Pediatric Nursing Journal, 34, 329-339.

[36] Skillen, D.L., Olson, J.K. and Gilbert, J.A. (2001) Framing Personal Risk in Public Health Nursing. Western Journal of Nursing Research, 23, 664-678. doi:10.1177/01939450122045474

[37] Larsson, L.S. and Butterfield, P. (2002) Mapping the future of environmental health and nursing: Strategies for integrating national competencies into nursing practice. Public Health Nursing, 19, 301-308. doi:10.1046/j.1525-1446.2002.19410.x

[38] Wright, D.J. (2003) Collaborative learning experiences for nursing students in environmental health. Nursing Education Perspectives, 24, 189-191.

[39] DeGusman, P.B. and Kulbok, P.A. (2012) Changing health outcomes of vulnerable populations through nursing's influence on Neighborhood built environment: A frame- 
work for nursing research. Journal of Nursing Scholarship, 44, 341-348. doi:10.1111/j.1547-5069.2012.01470.x

[40] Kuehn, A., Chircop, A., Downe-Wamboldt, B., SheppardLeMoine, D., Wittstock, L., Herbert, R., et al. (2011) Evaluating the impact of a North American nursing exchange program on student cultural awareness. Internatio- nal Journal of Nursing Education Scholarship, 35, 1-15. doi:10.2202/1548-923X.1919

[41] Burger, S. (2003) Case study of organizational and community health changes under New Jersey State Welfare reform. Policy, Politics, \& Nursing Practice, 4, 153-160. doi:10.1177/1527154403004002010 